\title{
A Resource Based View Of Manufacturing Strategy And Implications To Organizational Culture And Human Resources
}

Terrence J. Moran, St. Bonaventure University, USA

Peter Meso, Georgia State University, USA

\begin{abstract}
This paper purports that manufacturing strategy is a strategic asset. To prove that manufacturing strategy is valuable, it is determined that manufacturing strategy is linked to manufacturing success which is linked to business success. To capitalize on manufacturing strategy as a strategic asset, the factors that influence a successful strategy are determined.
\end{abstract}

Keywords: Human Resources, Manufacturing Strategy, Strategic Asset, Resource Based View

\section{INTRODUCTION}

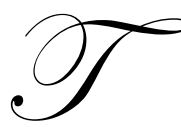

here is a common belief that manufacturing is an important part in corporate success. And yet, there is a lack of understanding of how manufacturing strategies can truly be a strategic asset (Roth, 1992).

This paper purports that manufacturing strategy is a strategic asset. The resource- based view defines a strategic asset as one that is rare, valuable, imperfectly imitable and non-substitutable. To prove that manufacturing strategy is valuable, it is determined that manufacturing strategy is linked to manufacturing success which is linked to business success.

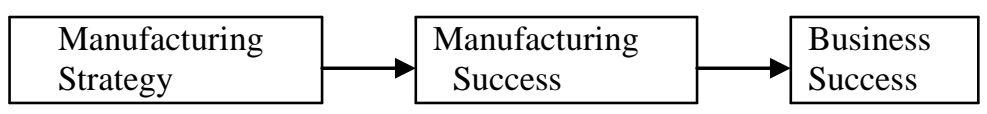

To capitalize on manufacturing strategy as a strategic asset, the factors that influence a successful strategy are determined.

Finally, if manufacturing strategy is a strategic asset, then the implications on Human Resource Department and Human Resource decisions are presented.

This paper builds on knowledge from A. Roth and J. Miller ("Success Factors in Manufacturing"), W. Skinner ("Manufacturing-Missing Link in Corporate Strategy"), S. Brown ("Manufacturing Strategy, Manufacturing Seniority and Plant Performance in Quality") and M. Michalisin, R. Smith, and D. Kline ("In Search of Strategic Assets"). 


\section{Definition Of Manufacturing Strategy}

In spite of all the chaos and turbulence in markets a clear strategy can play a significant part in a company's success. This is supported by Hayes and Pisano (1994), "In today's turbulent and competitive environment, a company more than ever needs a strategy that specifies the kind of competitive advantage that it is seeking in the marketplace and articulates how that advantage works" (Brown, 1998; Peters, 1987; Stacey, 1993).

There are key characteristics, which distinguish between strategic and tactical decisions. First, we can say that strategy formulation - and ultimate decision making authority - tends to involve senior management within the corporation even though other levels of the firm may be involved in the development of strategic plans and these other levels will be certainly be involved in their implementation. Next, we can add that strategic decisions are intended to create competitive advantage for the firm. Third, the result of a strategic decision can be both profound and have long term implications for the firm (Brown, 1998; Chandler, 1962; Dodgsoon, 1989; Evered, 1983; Hax, 1991; Porter, 1985).

The term "manufacturing strategy" remains noticeable by its absence in mainstream literature on "strategy". The possibility that there might be a manufacturing strategy comes, for some organizations, as a surprise. In manufacturing publications, the actual explicit term "manufacturing strategy is relatively new although it can be traced back to Skinner. Since the 1980s the phrase "manufacturing strategy" has become increasingly common. There is some confusion in terms of both when and where manufacturing strategy appears in the overall strategic planning process of the firm. It has been asked whether manufacturing strategy has been replaced by concepts such as JIT and TQM. Managers often find it hard to tell the difference between programs such as JIT and manufacturing strategy (Brown, 1998; Brown, 1996; Clark, 1996; Clark and Hayes, 1988; Hayes and Wheelwright, 1984; Hill, 1995; Mills, 1995; Skinner 1985).

Two definitions seem to sum up best what manufacturing strategy is.

1. "Manufacturing strategy consists of a sequence of decisions that over time, enables a business unit to achieve a desired manufacturing structure, infrastructure and set of specific capabilities." (Hayes and Wheelwright, 1984).

2. "Manufacturing strategy is viewed as the effective use of manufacturing strengths as a competitive weapon for the achievement of business and corporate goals" (Swamidass, 1987).

\section{Manufacturing Success Leads To Business Success}

There is a common belief that manufacturing is an important part in corporate success. And yet, there is a lack of understanding of how manufacturing success is linked to corporate success. "It is quite possible for a firm to be successful with a bad manufacturing strategy and fail with a good one. In other words, manufacturing matters, but not unconditionally" (Roth, 1992). To establish a link between manufacturing success and business success, it must be first determined how manufacturing strategy relates to three areas:

1. Relative Managerial Success

2. Relative Manufacturing Success

3. Economic Success (which signifies business success).

To determine these relationships data was derived from the 1988 Manufacturing Futures Project (MFP) by Roth and Miller, 1992. The data pertains to the responses of 180 of 193 executives who full answered all questions specific to the analysis. Performance in three areas was determined in the following manner.

1. Managerial Performance Success: Performance was determined against five measures: overall performance of business unit, customer satisfaction rating, after-tax profitability, return on assets, and market share.

2. Manufacturing Success. Manufacturing Success was determined by asking the executives to rate themselves on 11 competitive capabilities. 
3. Economic Success. Economic Success is determined by absolute measures of objective business figures: pretax profits, return on assets, annual sales revenue, growth rate in sales, and market share of primary product.

The linkage between manufacturing success and business performance is indirect. To link manufacturing to overall business performance requires management to exploit manufacturing capabilities. The established linkage is: manufacturing success is linked to managerial success is linked to economic success (See figure 1). Superior manufacturing only improves the odds of relative business success; it is up to general management to seize the opportunity generated by a successful manufacturing (Roth and Miller, 1992).

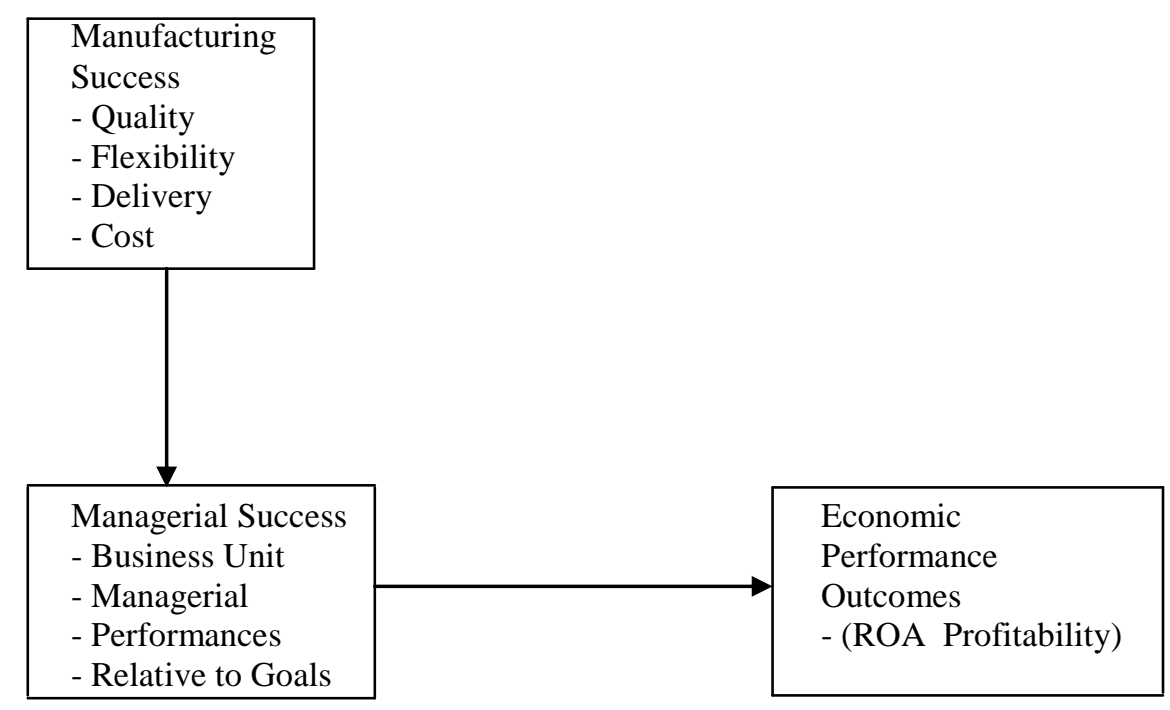

Figure 1

(Roth and Miller, 1992)

\section{Manufacturing Strategy Linked To Manufacturing Success}

Frequently the interrelationship between production operations and corporate strategy is not easily understood. The notion is simple enough-namely, that a company's competitive strategy at a given time places particular demands on its manufacturing function, and, operations should be specifically designed to fulfill the job demanded by strategic plans. What is more elusive is the set of cause-and-effect factors which determine the linkage from strategy to production operations (Skinner, 1969).

For most industrial corporations, the manufacturing operation is the largest, the most complex, and the most difficult to manage of the firm. Because of this, companies must have comprehensive manufacturing strategies (Fine, 1985).

The belief that manufacturing is an important ingredient in corporate and national success has spurred the development of manufacturing strategies in companies seeking competitive advantage around the world. Yet, the understanding of manufacturing strategies create competitive capabilities and profits is weak (Roth, 1992).

The link between manufacturing strategy and manufacturing success has been studied. The contributions of manufacturing strategies to subsequent manufacturing performance have been affirmed. Superior manufacturing capabilities are developed simultaneously, not sequentially. This suggests that developing strategic capabilities in manufacturing is dynamic, requiring a significant degree of attention to continuous transformation of the 
manufacturing environment. Key to the creation of superior manufacturing capabilities is the manufacturing strategy choices. Making the correct ones is the essence of manufacturing strategy (Brown, 1998; Roth, 1992).

\section{Implications Of Manufacturing Strategy On Corporate Strategy}

Since manufacturing strategy does play a part in manufacturing success and thus business success, it is important that manufacturing strategy be aligned with business strategy (Hill 1989). Manufacturing strategy is an important part of the firm's business strategies, comprising a set of well-coordinated objectives and action programs aimed at securing a long-term, sustainable advantage over competitors. Manufacturing strategy should be consistent with the firm's overall strategies, as well as with other functional strategies (Fine, 1985).

Manufacturing strategy cannot be formed in a vacuum; it affects and is affected by many organizational groups outside and inside the company. Because of the interrelationships among the firms' manufacturing unit, its divisions and other components, and its competitors and markets, the process of designing a manufacturing strategy must be carried beyond the borders of the firms' manufacturing organization (Figure 2). Initially in developing and implementing the strategy, manufacturing must work with finance, marketing, engineering and R\&D, personnel and purchasing. Working together and consistency of overall objectives are the keys to success in these interactions. Secondly, design of the manufacturing strategy must be based on careful monitoring of the firm's markets by manufacturing along with other functional groups. For example, manufacturing managers, in conjunction with the engineering group might monitor developments in electronics industry so that they are aware of new applications of electronics to process technology in their industry (Fine, 1985). Clearly, achieving long-term competitive advantage depends on the firm understanding how to position its manufacturing skills against its competitors (Buffa 1984; Fine 1985; Hayes 1984; Kantrow 1983).

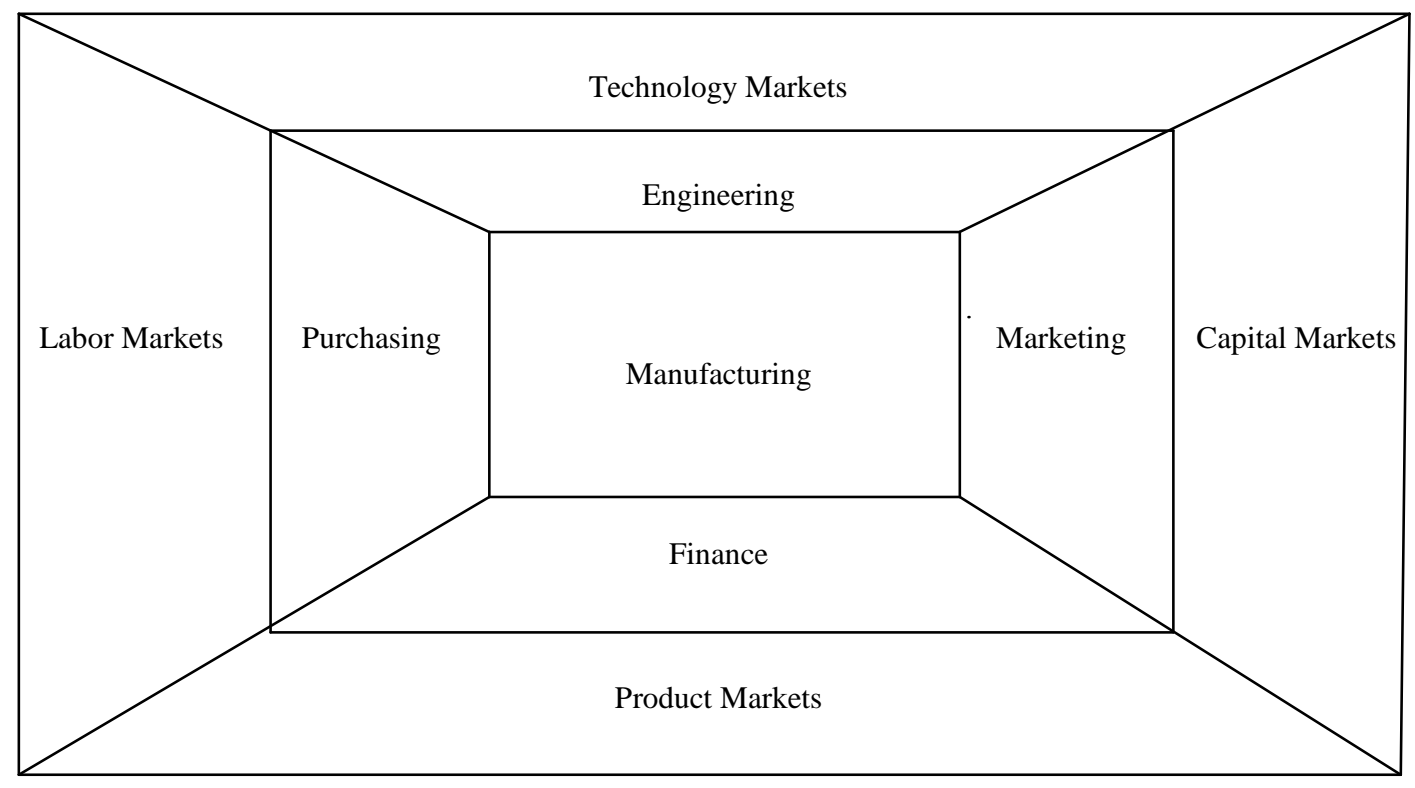

Figure 2

(Fine, 1985)

Manufacturing affects overall business strategy, and business strategy affects manufacturing. When corporations fail to recognize the relationship between manufacturing strategy and corporate strategy, they become burdened with seriously noncompetitive production systems, which are time consuming to change. The following is an example: 
Company A produced five kinds of electronic gear for five different groups of customers; the gear ranged from satellite controls to industrial controls and electronic components. In each market a different task was required of the production department. In spite of these highly diverse and contrasting tasks, production manager elected to centralize manufacturing facilities in one plant in order to achieve "economies of scale. What happened was that the demands placed on manufacturing by a competitive strategy were disregarded by the production group in order to achieve economies of scale. This manufacturing program satisfied no single division, and the serious marketing problems which resulted choked company progress.

The mistakes of considering low costs and high efficiencies as the key manufacturing objective in this example is typical of the simplified concept of a good manufacturing operation. Such criteria frequently get corporations into trouble, or at the very least do not help in the development of manufacturing into a competitive weapon (Skinner, 1969).

\section{Importance Of Seniority In Manufacturing}

There has been increasing importance placed on manufacturing personnel in terms of their contributions to the corporation's capabilities but not necessarily in terms of their seniority within the hierarchy of the corporation, which is a telling sign of manufacturing's role in many Western plants. Manufacturing personnel are, sometimes excluded from strategy formulation, by the fact of their position within the company, so that this is left to higher levels where there may not be any manufacturing presence. This despite the fact the current era of rapid change has the most profound impact on production/operations' activities within the company. The problem is that many corporations simply do not have senior manufacturing personnel in the ranks of "top management" with the firm (Brown, 1998; Hill, 1995; Lazonick, 1990; Skinner, 1969).

Manufacturing has too long been dominated by experts and specialists. As a result, top management tends to avoid involvement in manufacturing policy making, manufacturing managers are ignorant of corporate strategy and a function that could be a valuable asset and tool of corporate strategy becomes a liability instead. Top management can correct this problem by having senior level manufacturing managers involved in corporate strategy. These senior level managers, must also have a senior status in the corporation hierarchy, manufacturing must be on par with all departments. Also, senior manufacturing managers must be versed in managing, versus being technically proficient. Manufacturing involves trade-offs, and this requires a manager who can see the entire corporation as a system, not just one corner of it. i.e. the manufacturing factory (Skinner, 1969).

Manufacturing personnel need to be involved in business areas, and not merely as technical input. The role and involvement of senior manufacturing personnel is an important factor for three reasons:

1. They help champion the quality drives within the manufacturing function.

2. They provide guidelines and direction in areas such as training and quality manuals

3. Because of their involvement in the business of the plant, they were instrumental in translating customer requirements into operational capabilities throughout the plant (Brown, 1998).

\section{LINK BETWEEN CULTURE AND MANUFACTURING STRATEGY}

This paper builds on Skinner's proposition that manufacturing decisions have strategic implications and that manufacturing decisions should be aligned with business strategy. There has been little study of those factors which may enable or impede the use of manufacturing strategy to guide decision making at the manufacturing level. Since manufacturing strategy in guiding manufacturing decision making is ultimately determined at the plant level, more attention should be focused on organizational factors which may affect it, such as the organizational culture of the manufacturing plant. Figure 3 depicts the relationship between manufacturing strategy and organizational culture (Anderson, 1989; Bates, 1995; Hayes, 1984; Hill, 1989; Leong, 1990; Skinner, 1969). 


\section{Organizational Culture and Manufacturing Strategy-}

Conceptual Relationship

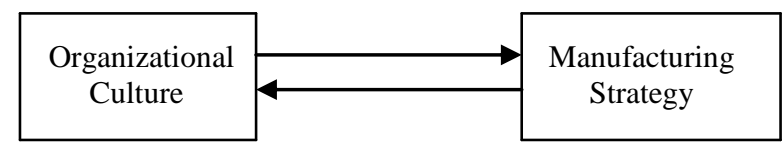

Figure 3

(Bates, 1995)

1. Defining Organization Culture:

Organizational culture has been used as a holistic construct that describes the complex set of knowledge structures which organization members use to accomplish and generate social behavior (Bates, 1995). Schein (1985) defines culture as, "a pattern of basic assumptions-invented, discovered, or developed by a given group as it learns to cope with its problems of external adaptation and internal integration-that has worked well enough to be considered valid and, therefore, to be taught to new members as the correct way to perceive, think, and feel in relation to those problems."

Organizational cultures have been characterized as hierarchies or clans based on the dominant form of control over individual actions within each cultural form. Hierarchies refer to organizational control through authority relationships, and clans refer to organizational control via the use of shared values and beliefs. A hierarchical culture centers on individual roles and limits of authority, explicit definitions of tasks, and precise measurement of narrowly defined elements of the production system. Since hierarchical cultures exert control through formal authority and role positions, they may be applicable for manufacturing systems which are relatively stable over time, which include tasks that are easily defined, measured and rewarded, which are buffered from other departments, and therefore operate relatively independently of the external environment. Clans apply control through the socialization of individuals and creation of common beliefs and values. A clan culture centers on common beliefs and values versus the narrowly defined roles. A clan culture centers on goal congruence among employees rather than direct supervision. A clan culture centers on guidance rather specific directives from management. A clan oriented culture my be most appropriate for manufacturing plants in which frequent introduction of new products and processes causes regular changes in the tasks and roles of employees, and in which frequent contact with other departments, suppliers, and customers reflects interdependence between the plant and the environment (Bates, 1995; Ouchi, 1979, 1980, 1981; Wilkens, 1983).

If manufacturing strategy and organizational culture are related, there are two forms that the relationship could take. First, well aligned and implemented manufacturing strategy could be connected with a clan oriented organizational culture. Secondly, a well aligned and implemented manufacturing strategy could be associated with a hierarchical organizational culture. This entails that manufacturing strategy is essentially a top-down process in which individuals in the plant react to manufacturing strategy as to other formal control mechanisms (Bates, 1995).

The relationship between manufacturing strategy and organizational culture in manufacturing companies was examined, and, and a well aligned and implemented manufacturing strategy was found to coexist with a clan oriented organizational culture. Manufacturing strategy and organizational culture were found to exhibit a statistically significant relationship within the manufacturing plant. The analysis signifies that a well aligned and implemented manufacturing strategy, which includes formal planning process, communication of strategy, contribution to competitive position, and a long range orientation, coexists with a clan organization culture. This clan organization culture is characterized by the use of groups and teams, low emphasis on hierarchy, and high levels of loyalty with a share plant-wide philosophy (Bates, 1995). 


\section{MANUFACTURING STRATEGY IS A STRATEGIC ASSET}

Manufacturing Strategy is a strategic asset. As defined by the resource-based view, a strategic asset is one that is simultaneously valuable, rare, imperfectly imitable, and nonsubstitutable. Sustainable competitive success results only from strategic assets. According to the resource-based view, it is only the strategic assets that differentiate itself from competitors. These strategic assets are company reputation, product reputation, employee know how, and organizational culture (Meso, 1999; Michalisin, 1997; Smith 1999).

A resource is valuable if it allows the firm to capitalize the opportunities in the market or to hinder competitive threats. Clearly, as has been demonstrated, manufacturing strategy is valuable. Manufacturing strategy is linked to manufacturing success, which is linked to business success. Manufacturing strategy, when formed in conjunction with the corporate strategy, allows the firm to capitalize on the opportunities in the market (Meso, 1999; Michalisin, 1997; Smith 1999).

If the resource is imperfectly imitable, it can be sustained for long periods of time without competitors acquiring it or duplicating it. A manufacturing strategy is imperfectly imitable. The manufacturing strategy is linked to the company culture. Since company culture is a strategic asset, then the manufacturing strategy that is the result of this unique culture is also unique and imperfectly imitable. Manufacturing strategy is the result of the synergy of the company. This synergy is very difficult to duplicate. Manufacturing strategy is the result of the unique interactions of the people at the specific company (Meso, 1999; Michalisin, 1997; Smith, 1999).

If a resource is owned by a very small number of firms in the industry, then the resource is rare. Manufacturing strategy cannot be bought, it is formed. Because of this, each company forms its own unique strategy; therefore it is rare (Meso, 1999; Michalisin, 1997; Smith, 1999).

Next, a strategic asset is non-substitutable. It is non-substitutable if there are no strategic equivalents. What is the substitute of a manufacturing strategy? No manufacturing strategy. A "no manufacturing strategy" is not a substitute for a manufacturing strategy (Meso, 1999; Michalisin, 1997; Smith, 1999).

The resource-based view asserts that it's only the strategic assets that differentiate itself from competitors. The strategic assets allow firms to exploit physical technology in ways other firms can't (Michalisin, 1997).

\section{NEED A SYSTMES VIEW/LEARNING ORGANIZATION}

It has thus been demonstrated that a manufacturing strategy is a strategic asset.

This manufacturing strategy cannot be formed in a vacuum; it must be formed in conjunction with corporate strategy. Also, it has been demonstrated that the culture plays a role in manufacturing strategy. To enable manufacturing strategy be successful a systems approach is preferred. A systems approach facilitates team interactions, which can develop a successful manufacturing strategy. Figure 4 outlines the approach.

This systems approach capitalizes on the learning organization. As Henry Minztburg pointed out, planning cannot be formalized. Ideally, a manufacturing strategy is formed by utilizing creativity from the organization. Strategic thinking at every level so a learning organization is realized (Mintzberg, 1994). 


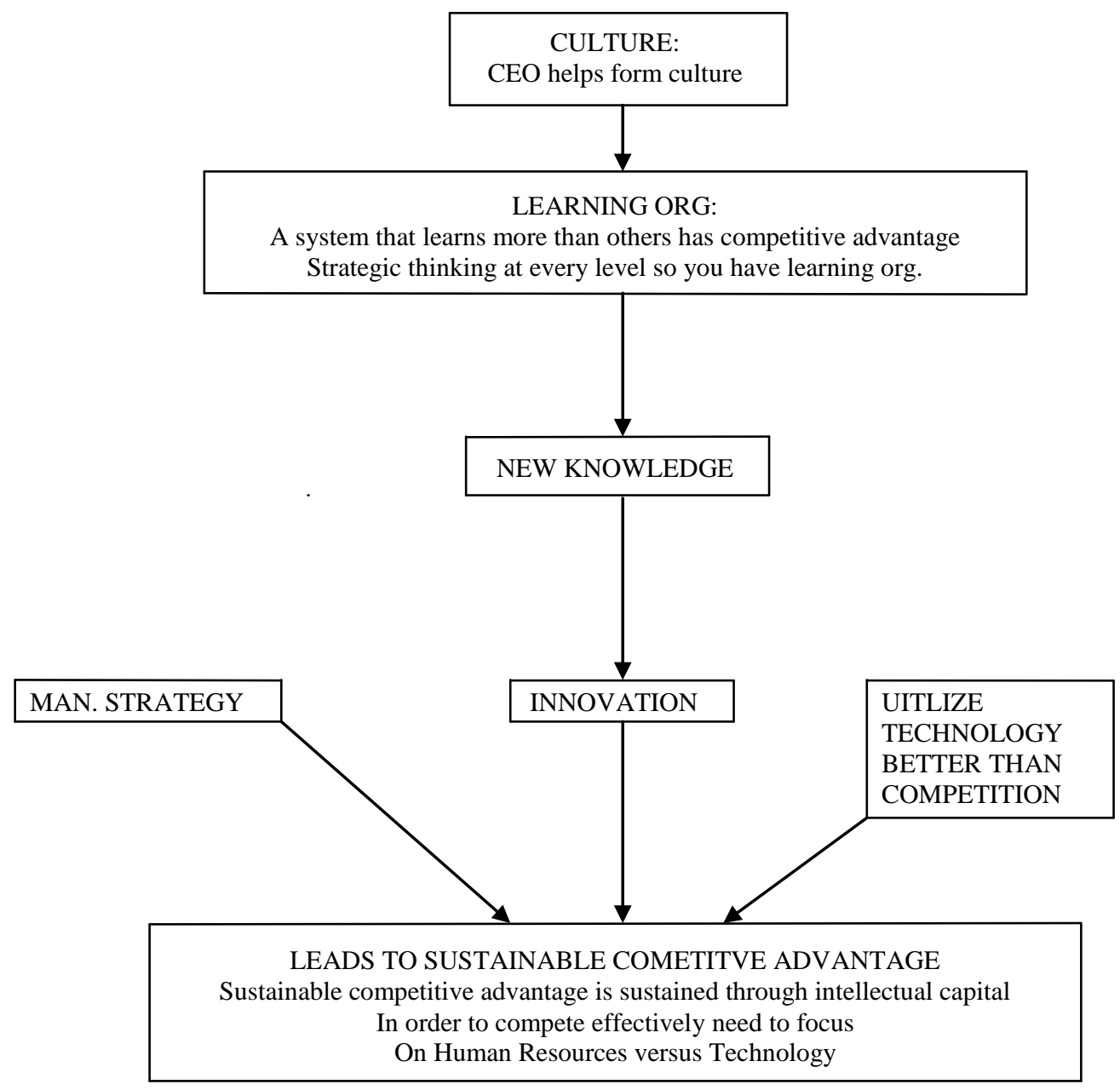

Figure 4

\section{IMPLICATIONS ON HUMAN RESOURCE}

Sustainable competitive advantage is sustained through strategic assets. As has been demonstrated, manufacturing strategy is a strategic asset. A successful manufacturing strategy is tied in with organization culture and a learning organization.

Since this strategic asset is important to a company's future, the main concern of managers should be in selecting, acquiring, and managing human resources superior to one's competitors. Companies need to focus on human resources that form the manufacturing strategy, versus technology which is not a strategic asset. Employees are the key source of intellectual capital. Intellectual capital in of itself is a strategic asset. Therefore, in order to develop superior manufacturing strategy, it is important to acquire superior intellectual capital. Human resources should be seeking intelligent people, since they will be developing the manufacturing strategy.

Also, it is key to get a good CEO, because CEO has direct effect on culture, which has affect on the manufacturing strategy. Human resources should consider hiring a CEO outside of the organization, in order to facilitate an open system. An open system has exchange of information, versus a closed system which can die out if there is a lack of influx of knowledge. 
A systems approach increases the probability of developing a successful manufacturing strategy. Human resources must facilitate this systems approach, seeking to create a learning organization, an organization that is flatter, with interactions of teams. Human resources should be hiring people who can fit into this team approach. Strategy does not form in a vacuum, need to create the holistic approach to strategy formation.

Another issue for human resources is the lack of seniority of manufacturing personnel. The problem is that many corporations simply do not have senior manufacturing personnel in the ranks of "top management" with the firm. Human resources should be advocating the need for this manufacturing seniority to the CEO. Someone has to push for these ideas, and that would be the proper function of the human resource department. Of course this assumes that the human resource has influence in corporate strategy and the HR department has a rank of "top management" in the firm, which is not always the case.

\section{CONCLUSION}

This paper has shown the link from manufacturing strategy to manufacturing success to business success. By establishing this linkage, it laid the foundation to prove that manufacturing strategy is a strategic asset. The resource-base view defines a strategic asset as rare, valuable, imperfectly imitable, and non-substitutable.

Factors that influence the creation of manufacturing strategy are culture and organizational structure. Manufacturing strategy would be positively influenced by a systems approach, capitalizing on the synergy of the whole organization in a holistic way. Manufacturing strategy cannot be formed in a vacuum; it must be formed in conjunction with overall business strategy.

The role of Human Resources is to be an advocate of a systems approach in a way to create a learning organization. The HR department should be hiring intelligent people, people who can produce creative manufacturing strategy. Since there is a link from CEO to culture to manufacturing strategy, then HR department should focus on hiring a quality CEO, preferably someone outside the organization. Also, The HR department should push for senior manufacturing personnel to the ranks of "top management."

These recommendations do not guarantee success. It is quite possible for a firm to be successful with a bad manufacturing strategy and fail with a good one. These recommendations increase the probability of creating a successful manufacturing strategy, and thus increase the probability of obtaining business success.

Future research could focus on the effect of manufacturing strategy on culture. How does cultural change contribute to the effective installation of manufacturing strategy? Research is also needed to analyze the process of implementing manufacturing strategy and associated changes in organization (Bates, 1995).

\section{AUTHOR INFORMATION}

Terrence J. Moran is an assistant professor in the school of business at St. Bonaventure University. Research interests include Operations Management - waiting line studies, and simulation studies of production systems. School of Business, St. Bonaventure University, St. Bonaventure, NY 14778

Peter N. Meso is an assistant professor of Information Systems at Georgia State University. Research interests deals with contributions of software engineering in knowledge management and emerging business information systems and infrastructure.

Email: pmeso@cis.gsu.edu

\section{END NOTES}

1. Anderson, John C., Gary Cleveland and Roger G. Schroeder, "Operations Strategy: A Literature Review," Journal of Operations Management, April 1989, pp. 133-158. 
2. Bates, Kimberly A., Susan D.Amundson, Roger D. Schroeder and William T. Morris, "The Crucial Interrelationship Between Manufacturing Strategy and Organizational Culture," Management Science, Volume 41, October 1995, pp. 1565-1580.

3. Brown, Steve, "Manufacturing Strategy, Manufacturing Seniority and Plant Performance in Quality," International Journal of Operations and Production Management, Volume 18 No. 6, 1998, pp. 565-587.

4. Brown, Steve, Strategic Manufacturing for Competitive Advantage, Prentice-Hill, Hemel, Hempstead: 1996.

5. Buffa, Elwood S., Meeting the Competitive Challenge-Manufacturing Strategy for U.S. Companies, Richard D. Irwin, Homewood, Illinois: 1982.

6. Chandler, A., Strategy and Structure: Chapters in the History of the American Industrial Enterprise, Irwin, USA: 1962.

7. Clark, K, "Competing Through Manufacturing and the New Manufacturing Paradign: Is Manufacturing Strategy Passe?," Industrial and Corporate Change, Volume 1 No. 2, 1996.

8. Clark, K. and R. Hayes, "Recapturing America's Manufacturing Heritage," California Management Review, Summer, 1988.

9. Dodgson, M., Technology Strategy and the Firm, SPRU/Longman, UK: 1989.

10. Evered, R., "So What is Strategy?,"_Long Range Planning, Volume 16 No. 3, June, pp. 55-72.

11. Fine, Charles H. and Arnoldo C. Hax, "Manufacturing Strategy: A Methodology and an Illustration," Interfaces, November-December, 1985, pp. 28-46.

12. Hax, A. and N. Majluf, The Strategy Concept and Process, Prentice-Hill, Englewood Cliffs, NJ: 1991.

13. Hayes, R. and G. Pisano, "Beyond World-Class: The New Manufacturing Strategy,"Harvard Business Review, January-February, 1994, pp. 77-86.

14. Hayes, Robert J. and Steven C. Wheelwright, Restoring_Our Competitive Edge: Competition Through Manufacturing, John Wiley and Sons, New York: 1984

15. Hill, Terry, Manufacturing Strategy, Macmillan, Basingstoke: 1995.

16. Hill, Terry, Manufacturing Strategy: Test and Cases, Dow Jones-Irwin, Homewood, IL:1989.

17. Kantrow, Alan M., Survival_Strategies for American Industry, John Wiley and Sons, New York: 1983.

18. Lazonick, W.,_Competitive Advantage on the Shopfloor, Harvard University Press, Cambridge, MA.: 1990.

19. Leong, G. K., D.L. Snyder and P.T. Ward, "Research in the Process and Content of Manufacturing Strategy," Omega International Journal of Management Science, Volume 18, 1990, pp. 109-122.

20. Meso, Peter, "A Resource-Based View of Organizational Knowledge Management Systems,” BAD 74261 Class, Kent State University, 1998.

21. Michalisn, M., Robert Smith and D. Kline, "In Search of Strategic Assets," The International Journal of Organizational Analysis, Volume 15 No. 4, October, 1997, pp. 360387.

22. Mills, J., K. Platts, and M. Gregory, “A Framework for the Design of Manufacturing Strategy Processes - A Contingency Approach International,” Journal of Operations \& Production Management, Vol. 15 No. 4 1994, pp. 17-49.

23. Mintzberg, Henry, "The Fall and Rise of Strategic Planning," Harvard Business Review, January-February, 1994, pp. 107-113.

24. Oouchi, William G., "A Conceptual Framework for the Design of Organizational Control Mechanisms," Management Science, Volume 25, September 1979, pp. 833-848.

25. Oouchi, William G., "Markets, Bureaucracies, and Clans," Administrative Science Quarterly, Volume 25, March 1980, pp. 129-141.

26. Oouchi, William G., Theory Z, Avon Books, New York: 1981.

27. Peters, T., Thriving on Chaos, Pan Books/Macmillan, London: 1987.

28. Porter, M., Competitive Strategy, Free Press, New York, NY: 1985.

29. Roth, Aleda V. and Jeffrey G. Miller, "Success Factors in Manufacturing," Business Horizons, July-August 1992, pp. 73-81.

30. Schein, Edgar H., Organizational Culture and Leadership, Jossey-Bass, San Francisco: 1985.

31. Sheridan, John W., "The Global Economic Engine," Industry Week, May 20, 1996, pp.16-24.

32. Skinner, Wickham, "Manufacturing-Missing Link in Corporate Strategy," Harvard Business Review, Volume 47, May-June 1969, pp. 136-145. 
33. Skinner, Wickham, Manufacturing, The Formidable Competitive Weapon, Wiley \& Sons, New York, New York: 1985.

34. Smith, Robert, Class Notes from "Strategic Decision Making and Human Resource Management," Kent State University, Kent, OH.: Spring 1999.

35. Stacey, R., Strategic Management and Organizational Dynamics, Pitman, London: 1993.

36. Swamidaas, P. and W. Newell, "Manufacturing Strategy, Environmental Uncertainty, and Performance: a Path Analytical Model," Management Science, Volume 33 No. 3, 1987, pp. 509-534.

37. Wilkens, Alan L., and William G. Ouchi, "Efficient Cultures: Exploring the Relationships Between Culture and Organizational Performance,” Administrative Science Quarterly, Volume 28, 1983, pp. 468-481.

\section{NOTES}




\section{NOTES}

